\title{
Constraints Experienced and Suggestions by Farming Community in Adaptation to Climate Change in Karnataka: An Economic Analysis
}

\author{
Ravi Dupdal ${ }^{1^{*}}$ and B.L. Patil ${ }^{2}$ \\ ${ }^{1}$ ICAR-Indian Institute of Soil and Water Conservation, Research Centre, \\ Ballari-583 104, India \\ ${ }^{2}$ Department of Agricultural Economics, College of Agriculture, University of Agricultural \\ Sciences, Dharwad - 580 005, Karnataka, India \\ *Corresponding author
}

\section{Keywords}

Climate change,

Constraints in

adaptation,

Descriptive

statistics, Garrett

ranking technique,

Adaptability

measures

Article Info

Accepted:

04 January 2019

Available Online:

10 February 2019

\section{A B S T R A C T}

Climatic variability has the potential to affect countries highly dependent upon agriculture, resulting in food shortages, among other consequences. Therefore, people who depend on farming will require a myriad of adaptation strategies to mitigate adverse effects of climate change and maintain the livelihoods of farm families. Farmers practice variety of adaptability measures to mitigate and preclude the effect of climate change in agriculture. However, farmers come across varieties of constraints in adaptation in response to climate change. The paper reported the results of 240 farmers of northern Karnataka who are experiencing various constraints in adaptation in response to climate change and also enlisted various suggestions in order to negate the barriers to climate change. Descriptive statistics and Garrett ranking technique were employed for analyzing various socio-economic characteristics and constraints experienced by farmers in adaptation in response to climate change. The results shows that demographic composition was predominantly dominated by old age groups constituting $50.42 \%$ of surveyed farmers followed by middle aged category $(29.58 \%)$ and rest are young age groups $(20.00 \%)$. Higher proportions of farmers $(58.33 \%)$ were members of various social group participation. Little more than $1 / 3^{\text {rd }}$ of farmers involved in off-farm employment in the region. The main barriers to adaptation includes lack of knowledge and information about climate change and adaptation strategies (GS: 78.09), lack of access to timely weather forecast information (GS: 72.88) and timely availability of farm inputs (GS: 65.44) are attained I, II and III ranks respectively. Majority of the respondents $(75.00 \%)$ suggested that weather forecast should be accurate and available in time, whereas 69.58 per cent and 68.33 per cent of farmers suggests that Government support during natural calamities and timely supply of farm inputs on subsidized rate is necessary in order to mitigate negative impact of climate change. 


\section{Introduction}

Climate change is possibly the most complicated and challenging environmental problem faced by the world today and is increasingly recognized as a potent threat to agriculture in general and to food security in particular. Climate change has become one of the greatest challenges that the global community is confronting within this $21^{\text {st }}$ century. The projected magnitude of such changes in climate and its diverse impacts has become a serious matter of concern all over the world (Stern, 2007). It is expected to be more in case of tropical and sub-tropical regions (UNFCC 2009, Parry et al., 2007) which has attracted attention of thinkers from almost all fields. Both the developed and developing countries are in a way to search how to minimize risk out of it. But, in the process the developing countries have become the worst sufferer. Because of lack of adequate financial and technological resources they find it extremely difficult to cope with the changing circumstances.

India, one of the developing countries in the world, is more vulnerable of the adverse impact as it is mostly located in tropics and is backed by poor socio-economic, demographic and institutional adversaries. The impact is more aggravate in the agricultural sector. In particular, the rural farmers, whose livelihoods mostly depend on agriculture, are likely to bear the brunt of adverse impacts. Similarly, the impact will be more severe in rainfed area since most of the farmers in rainfed area depend on monsoon rainfall. Furthermore, major impacts of climate change will be on rainfed crops, which is cultivated nearly 60 per cent of area in India. Under such circumstances, adaptation to climate change could be one of the better options available for developing countries like India to counter the heavy burden of climate change. There are various studies in the literature which reflects that with adaptation the risk to climate change can be reduced or minimized to a greater extent and without adaptation it can be harmful for the agricultural sector (Smit et al., 2006; Guiteras, 2007; Reidsma et al., 2010; Deressa et al., 2010). Farming is predominant activity in rainfed region, and adaptive capacity brings ability of a farming system to adjust to climate change (including climate variability and other weather based extremes), to moderate potential damages. It helps to take advantages of preventive opportunities and to cope with the consequences. Farmers' generally practice different adaptability measures over the period to mitigate and prevent the effect of climate change in the farming.

Barriers to adaptation vary across countries, lack of credit/ savings (Institutional) is observed main constraint. Access to water is another bottleneck for adaption in countries like Africa and South Asia (Kelkar and Bhadwal, 2007; Glwadys, 2009). Keeping in view the present study attempts to examine the various constraints experienced by farmers in response to climate variability in northern part of Karnataka.

\section{Materials and Methods}

The study was conducted in Northern part of Karnataka by interviewing over 240 sample farmers. The data required for study from the respondents were gathered through multi stage random sampling technique. In the first stage, two districts namely Vijayapura and Bagalkote were selected purposively. In the second stage, two taluks from each district were selected for collection of primary data. In the third stage, two villages were selected randomly from each taluks. Thus total sample of about 240 were collected from representative sample farmers. The primary data were collected during 2016 using pre- 
tested and well structured interview schedule. The data were then scored, tabulated and analyzed using various suitable statistical tools.

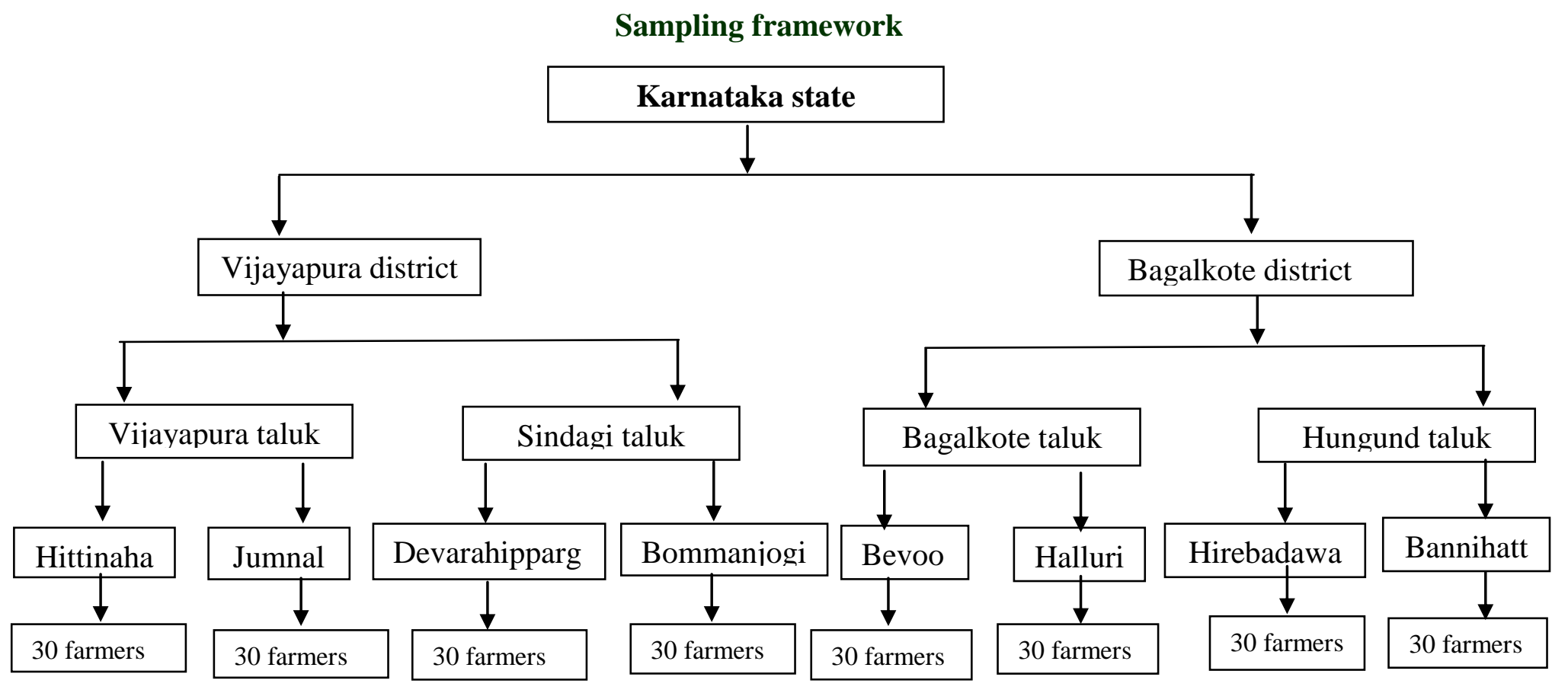

\section{Descriptive statistics}

The results of the study were presented in tabular and descriptive forms. Descriptive statistical tools such as frequency distribution, percentages and averages were employed to analyze the various socio-economic characteristics of sample respondents of Vijayapura and Bagalkote district of northern part of Karnataka.

\section{Garrett ranking technique}

Garrett ranking technique was employed for analyzing the various constraints experienced by sample farmers in adaptation in response to climate change. Correspondingly, ranks were assigned for each constraints based on Garrett mean score. The main advantage of this technique over simple frequency distribution is that the strategies are arranged based on their weights/importance from the point of view of respondents. Hence, the same number of response on two or more strategies may get different ranks. Garrett's formula for converting normal rank into per cent was given by:

Per cent position $=100 \times\left(\mathrm{R}_{\mathrm{ij}}-0.5\right) / \mathrm{N}_{\mathrm{j}}$

Where,

$\mathrm{R}_{\mathrm{ij}}=$ rank given for $\mathrm{i}^{\text {th }}$ factor by $\mathrm{j}^{\text {th }}$ individual;

$\mathrm{N}_{\mathrm{j}}=$ number of factors ranked by $\mathrm{j}^{\text {th }}$ individual

The per cent position of each rank is converted into scores referring to the table given by Garrett and Woodworth (1969). For each strategy, the scores of individual respondents are added together and divided by the total number of the respondents for whom scores are added. These mean scores for all the factors are arranged in descending order, ranks are given and most important factors are identified. 


\section{Results and Discussion}

\section{Socio-economic characteristic of sample farm households}

The results of socio-economic characteristics of sample farmers are presented in Table 1. The study of socio-economic characteristics of sample farmers shows that demographic composition was predominantly dominated by old age group (more than 46 years) constituting $50.42 \%$ of surveyed farmers followed by middle age group category $(29.58 \%)$ and rest are young age groups $(20.00 \%)$. The majority of farmer's secured primary education $(40.00 \%)$ and very less number of farmer's access graduation $(12.50 \%)$. The education level of farmer's is very important implication on technology adoption and its usage. Most of farmers in the region prefer small (49.58\%) and nuclear family $(53.34 \%)$.

Majority of farmers (52.08\%) possess 16 to 25 years of farm experience and larger proportions of farmers $(58.33 \%)$ were members of various social group like farmers club, self-help groups and members of non government organization (NGOs). The larger participation and greater involvement of farmers to such social groups can enhance their knowledge and awareness about modern agriculture technologies or schemes available to farmers. Little more than $1 / 3^{\text {rd }}$ of farm household involved in off-farm employment activities. Adversities caused by change in climate and frequent failure of monsoon in the recent years, opted for non-farm employment strategy to overcome the negative impact of climate change and also to meet daily expenditure. It helps for enhancing their farm income due to adoption of various technologies. Further studies found that majority of farmers are small $(33.75 \%)$ and medium $(30.00 \%)$ land holding category.
Constraints experienced by the farmers for adaptation in response to climate change

The present study also assessed various constraints experienced by farmers in adaptation to climate change in agriculture and allied activities (Table 2). For each sample respondents are allowed to rank their preferences and this was explained by using Garrett ranking technique.

The constraints to adaptation to climate change among the respondents (Table 2) show that the main hindrance to adaptation to climate change among the respondents includes lack of knowledge and information about climate change and adaptation strategies (GS: 78.09), lack of access to timely weather forecast information (GS: 72.88) and timely availability of farm inputs (GS: 65.44) are attained I, II and III ranks respectively. Lack of information was also identified as the main barrier for adaptation to climate change by a survey in Nile Basin of Ethiopia (Deressa et al., 2010). Unpredictability of weather condition coupled with limited accessibility of information from weather forecasts makes it difficult for sample farmers to plan ahead.

Similarly, lack of accessibility of water and irrigation facility aggrieved the situation in study region since most of the study districts include under rainfed/dryland conditions and poor accessibility of agricultural extension services and training to farmers are other major constraints experienced by

most of sample respondents in the region. The major factors hindering adaptation to climate change was mainly inadequate information, limited awareness and knowledge in regard to adaptation strategies and poor government policies to climate change phenomena (Nzeadibe et al., 2011) (Fig. 1). 
Suggestions made by sample farmers to overcome the constraints

The farmers in study region were also asked about their suggestions to overcome constrains faced by them in coping to climate change and presented in Table 3. Majority $(75.00 \%)$ of the respondents suggested that weather forecast should be more accurate and available in time, where as 69.58 per cent and
68.33 per cent of farmers suggests that Government support to farmers during natural calamities and timely supply of farm inputs on subsidized rate. The timely availability of both weather data well in advance of crop season and critical farm inputs is crucial for enhancing farm production by reducing the adverse affect of climate variability in the region.

Table.1 Socio-economic characteristics of sample farm household

$\mathrm{n}=240$

\begin{tabular}{|c|c|c|c|c|}
\hline SI. No. & Particulars & Category & Frequency & Percentage \\
\hline \multirow[t]{3}{*}{1} & Age & Young $(<35)$ & 48 & 20.00 \\
\hline & & Middle (36-45) & 71 & 29.58 \\
\hline & & Old $(>46)$ & 121 & 50.42 \\
\hline \multirow[t]{4}{*}{2} & Education & Illiterate & 58 & 24.17 \\
\hline & & Primary & 96 & 40.00 \\
\hline & & Higher secondary & 56 & 23.33 \\
\hline & & Graduation & 30 & 12.50 \\
\hline \multirow[t]{2}{*}{3} & Gender & Male & 211 & 87.91 \\
\hline & & Female & 29 & 12.09 \\
\hline \multirow[t]{3}{*}{4} & Family size & Small (up to 5) & 119 & 49.58 \\
\hline & (Numbers) & Medium (6 to 8) & 75 & 31.25 \\
\hline & & Large (more than 9) & 46 & 19.17 \\
\hline \multirow[t]{2}{*}{5} & Family type & Nuclear family & 128 & 53.34 \\
\hline & & Joint family & 112 & 46.67 \\
\hline \multirow[t]{3}{*}{6} & Farming & Low (up to 15 years) & 53 & 22.08 \\
\hline & experience & Middle (16-25 years) & 125 & 52.08 \\
\hline & (Years) & High (more than 25 years) & 62 & 25.84 \\
\hline \multirow[t]{2}{*}{7} & Social & Yes & 140 & 58.33 \\
\hline & participation & No & 100 & 41.67 \\
\hline \multirow[t]{2}{*}{8} & Access to & Yes & 154 & 64.16 \\
\hline & irrigation & No & 86 & 35.84 \\
\hline \multirow[t]{2}{*}{9} & Off-farm & Yes & 84 & 35.00 \\
\hline & occupation & No & 156 & 65.00 \\
\hline \multirow[t]{4}{*}{10} & Land holding & Marginal & 39 & 16.25 \\
\hline & type & Small & 81 & 33.75 \\
\hline & (Numbers) & Medium & 72 & 30.00 \\
\hline & & Large & 48 & 20.00 \\
\hline
\end{tabular}


Table. 2 Constraints experienced by the farmers for adaptation to climate change

\begin{tabular}{|c|c|c|c|}
\hline & & & $=240$ \\
\hline $\begin{array}{l}\text { Sl. } \\
\text { No. }\end{array}$ & Constraints experienced & Mean Garrett score & Rank \\
\hline 1. & Lack of access to timely weather forecast information & 72.88 & II \\
\hline 2. & Lack of adequate funds available with farmers & 38.53 & $\mathrm{XI}$ \\
\hline 3. & $\begin{array}{l}\text { Lack of knowledge about need based improved } \\
\text { agriculture technologies }\end{array}$ & 47.55 & IX \\
\hline 4. & $\begin{array}{l}\text { Lack of market access (Poor transportation networks } \\
\text { and market information system) }\end{array}$ & 43.15 & $\mathrm{X}$ \\
\hline 5. & Lack of credit or insurance service & 54.79 & VII \\
\hline 6. & Timely availability of farm inputs & 65.44 & III \\
\hline 7. & Limited access to agricultural extension services & 59.21 & $\mathrm{~V}$ \\
\hline 8. & Low/no subsidies on desired agricultural inputs & 36.05 & XII \\
\hline 9. & Lack of belief on current weather forecast system & 51.27 & VIII \\
\hline 10. & Irregularity in power supply & 55.65 & VI \\
\hline 11. & $\begin{array}{l}\text { Lack of knowledge and information about climate } \\
\text { change and adaptation strategies }\end{array}$ & 78.09 & I \\
\hline 12. & Lack of irrigation facility and access to water & 62.24 & IV \\
\hline
\end{tabular}

Table.3 Distribution of respondents according to their suggestions to minimize the constraints in adaptation to climate change

$\mathrm{n}=240$

\begin{tabular}{|c|l|c|c|}
\hline $\begin{array}{c}\text { Sl. } \\
\text { No. }\end{array}$ & \multicolumn{1}{|c|}{ Suggestions } & $\begin{array}{c}\text { No. of } \\
\text { farmers }\end{array}$ & $\begin{array}{c}\text { Percenta } \\
\text { ge }(\boldsymbol{\%})\end{array}$ \\
\hline $\mathbf{1 .}$ & Weather forecast should be more accurate and timely & 180 & 75.00 \\
\hline 2. & Accurate information need to be provided about climate change & 138 & 57.50 \\
\hline 3. & Credit and insurance facility need to be ensured & 156 & 65.00 \\
\hline 4. & Ensure farm inputs on subsidized rate on time & 164 & 68.33 \\
\hline 5. & Create awareness among farmers about the effect of climate change and its & 122 & 50.83 \\
\hline & consequences & & \\
\hline 6. & Effective extension services need to be available to the farmers & 135 & 56.25 \\
\hline 7. & Ensure irrigation facility to farmers & 148 & 61.67 \\
\hline 8. & Government support to farmers during natural calamities & 167 & 69.58 \\
\hline 9. & Ensure rainwater harvesting structure and farm ponds & 77 & 32.08 \\
\hline $\mathbf{1 0 .}$ & Regular supply of power /electricity & 95 & 39.58 \\
\hline
\end{tabular}

Source: Field survey 
Fig.1 Distribution of respondents according to their suggestions to minimize the constraints in adaptation to climate change

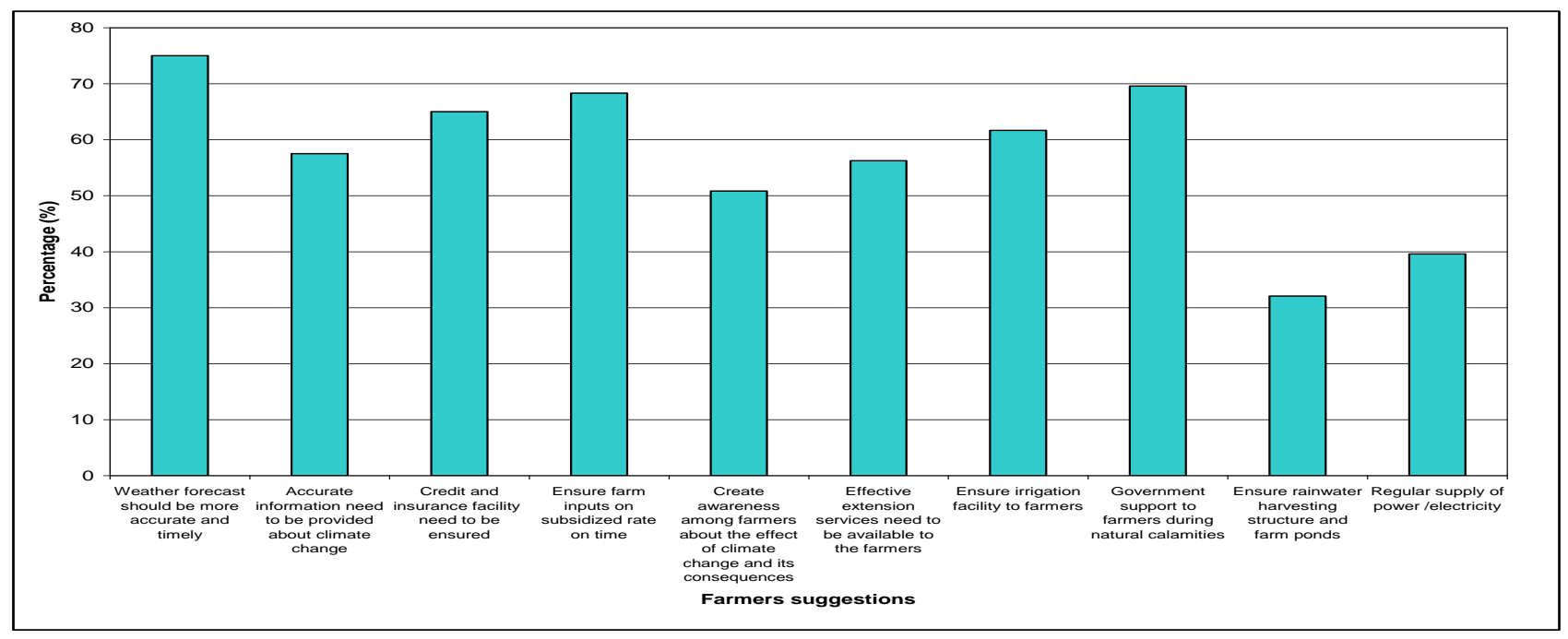

The other important suggestions were made by sample respondents are to minimize the constraints were credit and insurance facility need to be provided $(65.00 \%)$, ensure irrigation and water facilities to farmers for agricultural activities (61.67\%), accurate information need to be provided about climate change $(57.50 \%)$ and effective extension services at village levels need to be available to the farmers $(56.25 \%)$. Similarly, section of sample farmers also gave some more suggestions such as creating awareness among farmers about climate variability and its possible impacts on crop yield, regular supply of electricity at village level and creates awareness regarding water shaving technologies (rainwater harvesting structure and farm ponds). According to the farmers of study area above arrangements may help them to overcome constraints in adaptation against climate change.

In conclusion, farmers practices different adaptability measures over the period to mitigate and prevent the effect of climate change in the agriculture. However, farmers come across varieties of constraints in adaptation in response to climate change. The constraints may be personal, institutional and even technological with respect to climate change adaptation process. The major constraints faced by sample farmers in the region were lack of knowledge and information about climate change and adaptation strategies, lack of access to timely weather forecast information and timely availability of farm inputs. Farmers in the region specified some of important suggestion for minimizing the constraints in adaptation to climate change. Some of suggestions are weather forecast need to be more accurate and available in time, Government support to farmers during natural calamities and timely supply of farm inputs on subsidized rate. Therefore, it is advisable that policy of reliable and effective measures of adaptation need to be implemented and must be accessible to the end users. The government support and measures towards various adaptation strategies in reducing the constraints in adaptation is necessary so that farmers could cope up with changing climatic variability. 


\section{References}

Deressa, T. T., Ringler, C. and Hassan, R., 2010. The factors affecting the choices of coping strategies for climate extremes: The case of farmers in the Nile basin of Ethiopia. IFPRI Discussion paper No.1032, International Food Policy Research Institute (IFPRI), Washington, DC, USA, p. 35.

Garrett, H. E. and Woodworth, R. S., 1969. Statistics in psychology and education. Vakils, Feffer and Simon Pvt Ltd., Bombay: 329pp.

Glwadys, A., Gbetibouo., 2009. Understanding farmers 'perceptions and adaptations to climate change and variability: The case of the Limpopo Basin, South Africa. IFPRI Discussion paper No.849, Washington.

Guiteras, R., 2007. The impact of climate change on Indian agriculture. Working paper, Department of Economics, MIT

Kelkar, U. and S. Bhadwal., 2007. South Asian regional study on climate change impacts and adaptation: Implications for human development, Paper prepared by TERI for Human Development Report.

Nzeadibe, T. C., Egbule, C. L., Chukwuone, N. A. and Agu, V. C., 2011. Climate change awareness and adaptation in the Niger Delta Region of Nigeria. African Technology Policy Studies Network (ATPS) Working Paper Series, Nairobi: ATPS, p. 22.

Parry, M. L., Canziani, O. F., Palutikof, J. P., Linden, P. J. van der and Hanson, C. E., (Eds.), 2007. Contribution of working group II to the fourth assessment report of the intergovernmental panel on climate change, Cambridge university press, Cambridge, UK.

Reidsma, P., Ewert, F., Lansink, A. O. and Leemans, R., 2010. Adaptation to climate change and climate variability in European agriculture: The importance of farm-level responses. European J. Agron., 32, pp 91-102

Smit B., Wandel, J., 2006. Adaptation, adaptive capacity and vulnerability, Global environ change, 16, pp 282-292.

Stern, N., 2007. The economics of climate change: The stern review, Cambridge University Press: Cambridge, UK.

UNFCC, 2009. Climate change: Impacts, Vulnerabilities and adaptation in developing countries. www.unfccc.int/resource/docs/publicati ons/impacts.pdf.

\section{How to cite this article:}

Ravi Dupdal and Patil, B.L. 2019. Constraints Experienced and Suggestions by Farming Community in Adaptation to Climate Change in Karnataka: An Economic Analysis. Int.J.Curr.Microbiol.App.Sci. 8(02): 376-383. doi: https://doi.org/10.20546/ijcmas.2019.802.042 